\title{
Clinical Immersion for Biomedical Engineers: Pivoting to a Virtual Format
}

\author{
Ellen P. Brennan-Pierce (10, ${ }^{1}$ Susan G. Stanton, ${ }^{2}$ and Julie A. Dunn ${ }^{2}$ \\ ${ }^{1}$ School of Biomedical Engineering, Colorado State University, Fort Collins, CO, USA; and ${ }^{2}$ UCHealth North, Medical Center \\ of the Rockies, Loveland, CO, USA
}

(Received 30 June 2020; accepted 15 September 2020; published online 25 September 2020)

\section{CHALLENGE STATEMENT}

Throughout their curriculum, Biomedical Engineering (BME) undergraduate students become proficient in math, biomedical science, and their engineering specialization. BME senior capstone design courses often focus on medical device design, and we frequently hear from collaborators in the BME industry how important it is for young biomedical engineers to be exposed to clinical experiences to truly understand the environment and constraints that must be considered for successful design of medical devices. Furthermore, with clinicians being one of the major users of devices developed by biomedical engineers, it is valuable for biomedical engineers to spend time interacting with clinicians, learn the language of the clinical environment, and experience the state-of-the-art and present limitations of clinical care. However, there are very few opportunities for Colorado State University (CSU) BME students to gain significant exposure to clinical settings.

Experiential clinical programs for BME students can provide this opportunity, resulting in better preparedness to solve real-world problems, identify needs related to clinical settings, and apply knowledge learned in the classroom setting. ${ }^{1}$ Clinical simulationbased training and clinical immersion (CI) programs are two approaches to providing experiential clinical experience for BME students. Clinical simulationbased training has been found to be a valuable tool for BME students to practice hands-on real-world needs finding and device development. ${ }^{2}$ CI programs for BME students help students feel better prepared for

Address correspondence to Ellen P. Brennan-Pierce, School of Biomedical Engineering, Colorado State University, Fort Collins, CO, USA. Electronic mail: ellen.brennan-pierce@colostate.edu their capstone design experience, ${ }^{3}$ promote a strong understanding of user centered design, ${ }^{3,5}$ an improved ability to work with clinicians to define unmet needs, ${ }^{4,5}$ and positive impacts on the students' career interests and ability to find their first employment position. ${ }^{6}$ To bring CI opportunities to more BME students, NIH/ NIBIB has provided funding to create these programs at more than 25 institutions across the United States through the R25 "Team-Based Design in Biomedical Engineering Education". 6

Through this NIH/NIBIB funding mechanism, CSU and University of Colorado Health Medical Center of the Rockies (UCH-MCR) have run a collaborative summer CI program for BME students in summer 2018 and summer 2019. In this program, students attended patient rounds, observed surgical procedures and engaged with clinicians at UCH-MCR and related clinics, and interacted with product/device representatives on a full-time basis for 7 weeks. Weekly meetings were attended by the program participants and directors (a surgeon and a BME senior capstone design instructor), allowing for debriefing, additional questions and discussions related to participant experiences and observations from the previous week, and discussion of unmet clinical needs. When available, guests such as medical device product representatives gave lectures pertinent to product development. A senior capstone design project was developed each summer, based on needs assessment by the participating students and their discussions with clinicians. The capstone design project was then completed by an interdisciplinary student team within the BME senior capstone design course in the following academic year, with advising from a clinician and an industry engineer.

This CI program was planned to continue for summer 2020, but just after completing interviews with 
24 potential student participants in March, all in-person interactions at CSU were halted due to the COVID-19 pandemic. UCH also suspended the presence of all unnecessary personnel in their healthcare facilities to limit virus exposure. The program directors met in early May to make a final decision about cancellation of the program for summer 2020. During this meeting, the directors noted that the students had been very excited to participate in the program, and that many other summer programs and internships were cancelled, limiting options for students to have a meaningful professional experience during this unusual summer. Considering any option that might allow students some exposure to clinical processes and to clinicians themselves, the program directors identified this situation as a potential pivot point for a new modality and informally polled clinical contacts and the students that had been interviewed to determine if a virtual, remote CI program would be possible and of interest. After receiving overwhelmingly positive responses, planning for the virtual summer CI program began.

\section{NOVEL INITIATIVE}

Due to the limited time to coordinate all involved with the virtual program, the program start date was postponed 2 weeks from the original start date, and the program was shortened to 6 weeks. There was no way to replicate the volume of programming provided by the in-person program, so a compromise was reached. Three-hour meetings with guest clinicians and medical device sales representatives are held twice per week, and a one-hour group meeting is held once per week. The weekly group meetings are attended by the students and program directors (without guests) and allow for debriefing, additional questions and discussions related to topics from the previous week, and discussion of potential senior capstone design project ideas. The platforms used for the meetings are Google Meet and Zoom, chosen so guest clinicians and medical device sales representatives can share their screen easily with the program participants and directors. A representative screenshot from a Zoom CI meeting is shown in Fig. 1. The meetings are recorded, for future sharing and to allow flexibility for program participants if they have conflicts during meeting times. Program participants completed a non-disclosure agreement and gave consent to be recorded in the meetings.

The meetings include de-identified videos of medical procedures, clinician commentary of the videos, live video tours of hospital areas, clinician presentations, presentations and demonstrations by medical device sales representatives, and opportunities for Question and Answer sessions with the guests. Meeting recordings and related content are all posted on a shared Google drive so program participants can review these materials after meetings or if they miss a meeting.

Each week has a clinical department theme, similar to previous in-person rotation schedules. Departments were selected based on rotations that were most popular with students in previous years and requests from the current cohort of students. The curriculum for the program is shown in Table 1. To enable deeper engagement with the guest clinicians during the meetings, relevant journal articles, device descriptions, and videos are shared with participants before meetings to allow advanced reading and question preparation.

Finally, we expect that as in the previous years of the in-person program, discussions throughout the program about current medical devices and needs assessment will result in potential BME senior capstone design project ideas. Participants are responsible for independently researching the feasibility of project ideas so that the top project ideas can be determined during the last weekly group meeting.

\section{REFLECTION}

The virtual format allowed for more students to participate in the summer program. The in-person CI program provides a stipend for seven students each summer, and can accommodate up to nine additional volunteer students, for a maximum total of 16 students (limited due to space constraints). The in-person program supported seven stipend participants in the first summer, and seven stipend participants plus two volunteers in the second summer (all BME undergraduate students). For the virtual program, 22 students were able to participate since there were no space constraints. All 22 students participated on a volunteer basis, since this version of the program did not meet the NIH R25 requirements for stipend support. Because of the change in format and thereby relaxed requirements, five Biomedical Sciences undergraduate students and one Bioengineering graduate student were allowed to participate in the virtual program, along with $16 \mathrm{BME}$ undergraduate students. Allowing students from the Biomedical Sciences department to participate in the program increased the interdisciplinary aspect of the experience since these students bring different backgrounds and perspectives to the discussions.

An Institutional Review Board exempt anonymous pre- and post-program assessment survey regarding learning outcomes will be conducted. Individual exit interviews of the participants will be conducted to 


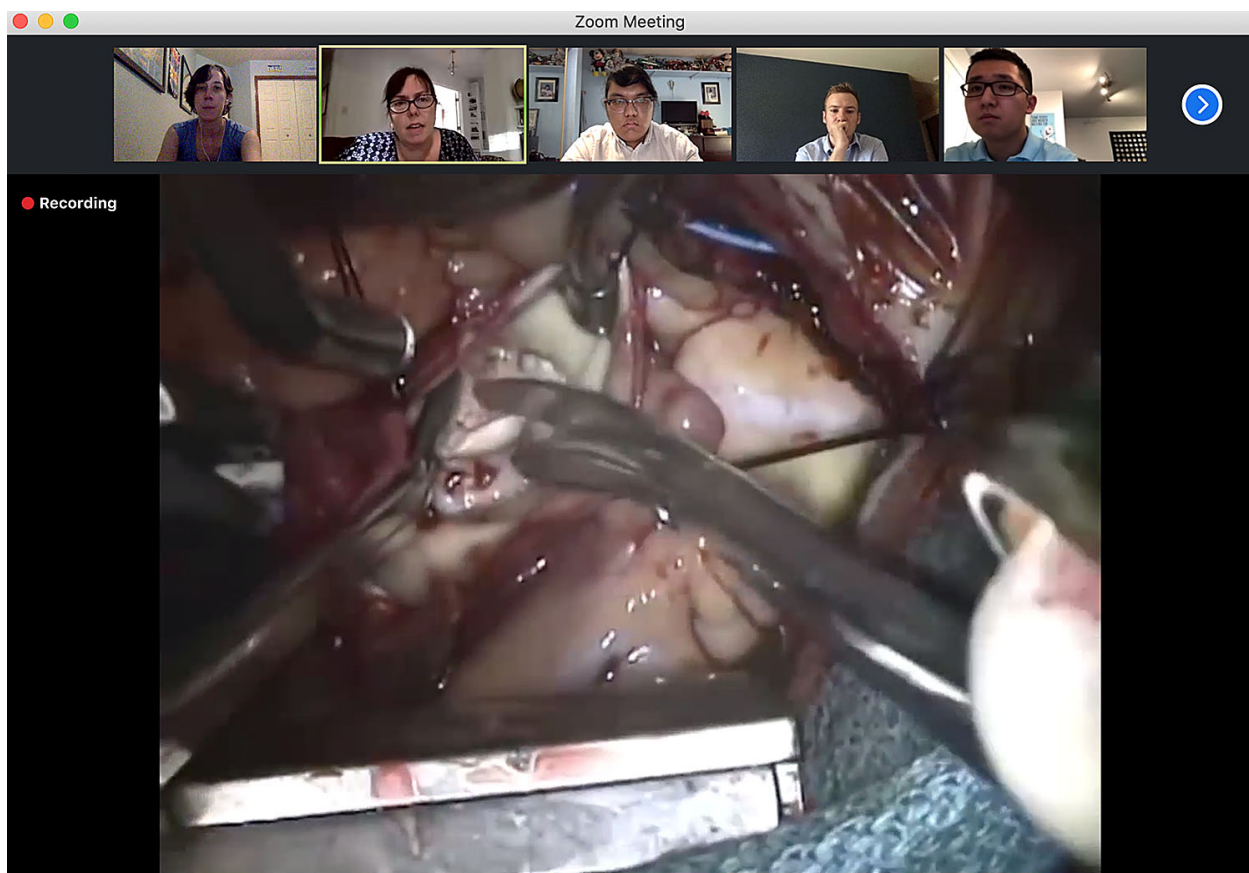

FIGURE 1. Representative screenshot from a virtual clinical immersion meeting, in which a clinician describes an aortic valve replacement surgery.

TABLE 1. Virtual clinical immersion program curriculum.

\begin{tabular}{|c|c|c|}
\hline Week & Department(s) & Topics \\
\hline 1 & Cardiology & $\begin{array}{l}\text { Aortic valve replacement, Transcatheter aortic valve replacement, Endovascular aortic repair and } \\
\text { thoracic endovascular aortic repair, thorascopic lobectomy, aortic root replacement }\end{array}$ \\
\hline 2 & $\begin{array}{l}\text { Cardiology, Intensive Care } \\
\text { Unit }\end{array}$ & $\begin{array}{l}\text { Electrophysiology, central lines, ultrasound, chronic total occlusion, coronary artery bypass grafting, } \\
\text { cardiopulmonary bypass and extra-corporeal membrane oxygenation }\end{array}$ \\
\hline \multirow[t]{3}{*}{3} & $\begin{array}{l}\text { Simulation Lab }{ }^{\mathrm{a}} \text {, Airlife, Radi- } \\
\text { ology }\end{array}$ & $\begin{array}{l}\text { Simulation lab will allow hands-on experience with obstretric issues and infant delivery, as well as } \\
\text { trauma skills stations to include chest trauma, airway emergencies, cardiac arrest and a Stop the } \\
\text { Bleed Course. During this session, participants will interact with high-fidelity mannequins and } \\
\text { discuss engineering principles of mannequin development }\end{array}$ \\
\hline & & $\begin{array}{l}\text { Realities of air and ground transport of emergency patients including ergonomics of ambulance } \\
\text { design }\end{array}$ \\
\hline & & $\begin{array}{l}\text { During the radiology portion emphasis will be placed on interventional radiology techniques and } \\
\text { devices }\end{array}$ \\
\hline 4 & Neurosurgery & Craniotomy, cavitron ultrasonic surgical aspirator, stealth system, deep brain simulator \\
\hline 5 & General Acute Care Surgery & $\begin{array}{l}\text { Robotic and laparoscopic procedures, rib plating, care of the COVID patient, forward surgical care in } \\
\text { the military arena, austere surgical care (Afghanistan, Syria and Iraq) }\end{array}$ \\
\hline 6 & $\begin{array}{l}\text { Oncology, Orthopedic Sur- } \\
\text { gery, Conclusion }\end{array}$ & $\begin{array}{l}\text { Dosimetry and radiation oncology, total knee replacement, orthopedic trauma, senior capstone } \\
\text { design project discussion }\end{array}$ \\
\hline
\end{tabular}

${ }^{a}$ The simulation lab will be completed in-person as in previous years because it is not located within the hospital and is a non-patient facility. This lab has multiple rooms which allow for social distancing. At the end of this experience the students will obtain certification in the 'Stop the Bleed' program offered by the American College of Surgeons Committee on Trauma.

determine strengths and weaknesses of the program. Exit interview questions are listed in Table 2.

The goals of the virtual CI program are the same as for the in-person program: provide general exposure to the clinical environment and its constraints through observation in several hospital departments, hands-on experience with mannequins in the Simulation Lab, discussion with users of medical devices, and needs finding leading to developing a senior capstone design project for the upcoming academic year. Learning outcomes of the virtual program are also the same as for the in-person program: understand the impact of 
TABLE 2. Individual exit interview questions for virtual clinical immersion program participants.

\author{
Exit interview question \\ Tell me about your three best experiences \\ Tell me what didn't work well \\ What would you tell other students about this experience? \\ If you were in charge, what would you change? \\ What was your favorite session? \\ What was your least favorite session? \\ Did anyone stand out as helpful and supportive? \\ Is there anything you want us to know to continue improving this program?
}

incorporating user needs, the user environment, and human factors into design solutions, and engage with clinicians. While these outcomes are met by the pivot to virtual format, the virtual format does not provide as many hours of clinical exposure $(6 \mathrm{~h}$ per week compared to $30-40 \mathrm{~h}$ per week in the in-person program). As a group, the students do not experience as great a breadth of situations in the virtual format since they all see the same videos and presentations, compared to the variety of situations that occur day-to-day in-person at the hospital. Consequently, we did not expect as many potential senior capstone design project ideas to be generated from this format, even though more students are participating in the program. Though fewer potential project ideas were discussed during the last group meeting this year compared to previous years (seven in 2018, six in 2019, five in 2020), two of these projects were of interest to industry engineers and clinicians and will be pursued in the upcoming academic year (compared to one project in 2018 and two in 2019). One significant benefit of the virtual format is that when clinicians show videos of medical procedures, the participants always have a very close view of the procedure and the clinician can pause the video to describe items of interest and answer questions in more detail. These opportunities are beneficial for needs finding and create an opportunity for deeper understanding of the topics covered.

Regarding clinician engagement in the pivot to virtual format, the CI program enjoyed success over the past 2 years in-person and was familiar to UCH-MCR clinicians. As elective procedures resumed we began to plan for the summer program and contacted clinicians who had hosted our students in previous years. While many expressed an interest in continuing to support the program in a virtual format, operationalizing this to a functional presentation proved difficult. Primary deterrents included: scheduling, increasing patient needs and demands as elective procedures were allowed to resume, and trepidation about the technology of the virtual platform. In general, UCH clin- icians enjoy teaching and have been and continue to be committed to sharing their expertise with learners who will become future engineers or providers. While essentially everyone involved in the in-person program voiced a willingness to participate virtually, schedule conflicts and a very short planning time frame did not allow participation in every case. Product representatives have been involved in previous years and were very willing to participate in the virtual format as it afforded them a great deal of flexibility. In several cases, clinicians recruited product representatives as adjunct support for their presentation. An added feature was the ability to recruit research and development engineers to participate virtually, which we hope to include in future experiences.

Overall the pivot to virtual format went well. Students responded very positively to live video tours of the Operating Room and Intensive Care Unit (clearly avoiding any patient disclosure) as they commented such tours made them feel more like they were there, and this experience prompted excellent questions and discussion from students. Sessions in which clinicians shared video footage of surgical or interventional procedures were also very well received. Students strongly voiced their appreciation for the programming we were able to deliver and stated they were grateful for our efforts to deliver any programming at all. There were occasional technical issues, but all involved recognized these minor difficulties as a common part of online interactions. One significant challenge was clinician schedules and availability. On several occasions, clinicians had emergency cases come up during the time they were scheduled to join our meeting. These instances required flexibility and improvisation from the program directors and other presenters on the schedule. In contrast, when these situations arose during the in-person program, the participant would simply join the emergency case or find something else to observe at that time at the hospital. 
COVID-19 continues to change how we approach education. This new environment created an opportunity to provide continued benefit to students through the creation of enduring content via meeting recordings, expansion of the experience to more participants, and the ability to share this experience with all CSU BME senior capstone design students through a library of meeting recordings. A similar library of virtual clinical rotations through video experiences has been used by others to bring clinical needs finding experience to senior capstone design classes, and students were able to identify unique needs through this method. ${ }^{7}$ This opportunity to greatly expand student exposure to the clinical perspective and environment will improve the background of all students in the CSU BME program.

\section{FUNDING}

Research reported in this publication was supported by the National Institute ofBiomedical Imaging and Bioengineering of the National Institutes of Health under Award NumberR25EB025791.

\section{ETHICS APPROVAL}

Colorado State University IRB exempt study protocol number $357-18 \mathrm{H}$.

\section{INFORMED CONSENT}

The publisher has the authors' permission to publish this contribution

\section{REFERENCES}

${ }^{1}$ Singh A, Ferry D, Mills S. Improving biomedical engineering education through continuity in adaptive, experiential, and interdisciplinary learning environments. J Biomech Eng. 2018;140(8):0810091-8.

${ }^{2}$ Singh A, Ferry D, Balasubramanian S. Efficacy of clinical simulation-based training in biomedical engineering education. J Biomech Eng. 2019;141(12):121011-121011-7.

${ }^{3}$ Kotche M. CI internship introduces students to needs assessment. In: ASEE annual conference 2016, 15593.

${ }^{4}$ Kadlowec J, Merrill T, Sood S, et al. CI and team-based design: into a third year. In: ASEE annual conference 2017, 19437.

${ }^{5}$ Felder AE, Kotche M, Stirling S, et al. Interdisciplinary CI: from needs identification to concept generalization. In: ASEE annual conference 2018, 21604.

${ }^{6}$ Kotche M, Felder AE, Wilkens K, et al. Perspectives on bioengineering $\mathrm{CI}$ : history, innovation, and impact. Ann Biomed Eng. 2020.

${ }^{7}$ Mittal V, Thompson M, Altman SM, et al. Clinical needs finding: developing the virtual experience - a case study. Ann Biomed Eng. 2013;41(9):1899-912.

Publisher's Note Springer Nature remains neutral with regard to jurisdictional claims in published maps and institutional affiliations. 